\title{
Estudo da Repassivação das Armaduras em Concretos Carbonatados através da Realcalinização Química com Solução de Hidróxido de Potássio
}

\author{
Carbonated concrete steel repassivation study through chemical realkalisation with \\ potassium hydroxide alkaline solution
}

Fernanda Araújo 1 (D) orcid.org/0000-0003-1316-1826

Antônio Melo Neto 2 (iD) orcid.org/0000-0003-3331-0577

Paulo Helene 3 (iD orcid.org/0000-0001-6442-7693

${ }^{1}$ Departamento de Engenharia Civil, UFRPE - Campus do Cabo de Santo Agostinho (UACSA), Recife, Brasil,

2 Departamento de Engenharia Civil, Universidade Federal de Pernambuco, Recife, Brasil,

${ }^{3}$ Universidade de São Paulo, São Paulo, Brasil.

E-mail do autor principal: Fernanda Araújo fernanda.wanderley@ufrpe.br

\section{Resumo}

A corrosão das armaduras por carbonatação é um dos fenômenos mais frequentes de deterioração das estruturas de concreto no Brasil. Apesar de ser um fenômeno que vem sendo muito estudado nos últimos anos, existindo parâmetros e recomendações para evitar sua ocorrência desastrosa em obras novas, ainda há muitas dúvidas e possibilidades de estudo. Este artigo apresenta o método de realcalinização química (RAQ), através da absorção e difusão de soluções alcalinas na superfície do concreto carbonatado. Neste estudo foram utilizadas três espécies químicas para obtenção das soluções alcalinas: carbonato de sódio, hidróxido de potássio, e hidróxido de cálcio. Para avaliar a eficácia desta nova técnica de reabilitação, foram realizadas medidas de profundidade de carbonatação e de realcalinização, medidas eletroquímicas de potencial de corrosão e de espectroscopia de impedância eletroquímica (EIE) para a verificação do estado da armadura, ensaios de imersão, absorção e ascensão capilar em concretos de controle (referência), carbonatados e realcalinizados. Com os resultados obtidos foi possível verificar que a solução de hidróxido de potássio propiciou tanto a realcalinização do concreto carbonatado, como também foi eficaz na repassivação das armaduras despassivadas.

Palavras-Chave: Concreto armado. Realcalinização. Repassivação. Potencial de corrosão. EIE;

\section{Abstract}

The corrosion of steel reinforcements in concrete due the carbonation is one of the principal causes of concrete structures deterioration in Brazil. There are parameters and recommendations to prevent its disastrous occurrence in new construction. However, there are still many gaps in knowledge of rehabilitation techniques in carbonated concrete. This paper presents the method of chemical 110 


\section{Estudo da Repassivação das Armaduras em Concretos Carbonatados através da Realcalinização Química com Solução de Hidróxido de Potássio}

realkalisation (CRA), through the absorption and diffusion of alkalis in the carbonated concrete surface, as a new technique of rehabilitation. The experimental program was conducted in three set of concrete specimens: reference, carbonated and CRA treated. The CRA method was studied with three types of alkaline solutions: sodium carbonate, potassium hydroxide and calcium hydroxide. To evaluate the effectiveness of CRA treatment was carried out measures of depths of carbonation and realkalisation; electrochemical measurements of potential and electrochemical impedance spectroscopy (EIS) to verify the condition of steel bars; immersion, absorption and capillary tests. The results showed that solution of potassium hydroxide realkalised the carbonated concrete, and the alkaline solution was effective on the steel repassivation.

Key-words: Reinforced concrete. Realkalisation. Repassivation. Corrosion potential. EIS.

\section{Introdução}

A realcalinização química (RAQ) ou natural em concretos carbonatados tem a finalidade de elevar o $\mathrm{pH}$ deste concreto empregando soluções rica em álcalis, mas sem o uso de corrente elétrica.

A realcalinização química, ilustrada na Figura 1 [1] consiste na absorção e difusão de soluções alcalinas por ação capilar e de forças hidráulicas para o interior do concreto carbonatado, não dependendo de aplicação de campo elétrico e de fluxo de corrente, como é o caso da realcalinização eletroquímica.

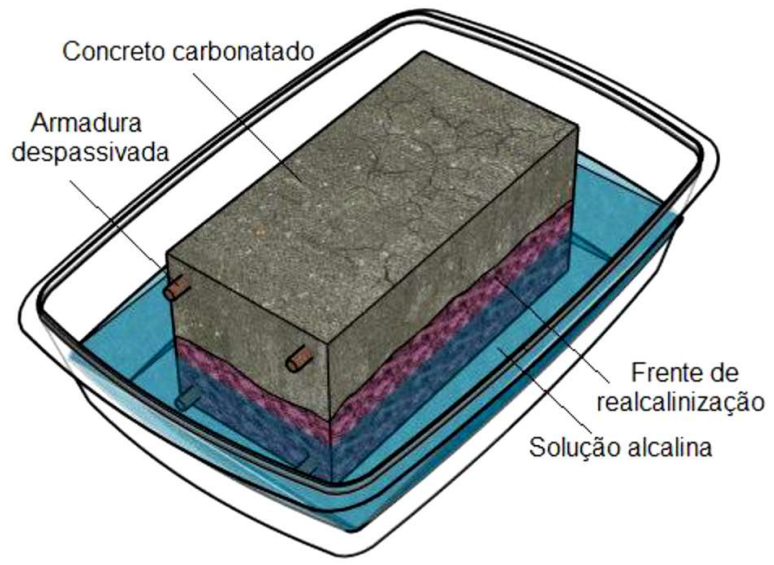

Figura 1: Esquema da realcalinização química pelo método de imersão. Fonte: Reus (2017).

A realcalinização química do concreto carbonatado acorre de fora para dentro, através dos capilares dos poros do concreto. Nos quais a forças hidráulicas farão com que a solução alcalina seja absorvida para o seu interior. Neste ínterim, os íons alcalinos contidos na solução reagem com os produtos contidos na água dos poros formando novos produtos. Estes novos produtos 111 formados propiciam a elevação do $\mathrm{pH}$ do concreto, assim como a fixação dos álcalis no interior do mesmo até atingir a região da armadura, provocando a sua repassivação [2].

Umas das soluções alcalinas estudas para a realcalinização química dos concretos carbonatados foi a de hidróxido de potássio, na concentração molar de 2,5M [2]. Esta solução, de acordo com a autora, obteve a maior velocidade de realcalinização quando comprada com as outras duas soluções estudadas, a de carbonato de cálcio e uma mistura chamada de tripla. A velocidade realcalinização química pelo método de imersão com a solução de hidróxido de potássio também foi comprovada através dos estudos realizados por pesquisadores da UFG [3 e 4] e da UFPR [1].

Assim, este trabalho teve como objetivo o estudo da eficácia da realcalinização química com solução de 2,5M de hidróxido de potássio na repassivação das armaduras imersas em concreto carbonatado. Os corpos-de-prova de concreto armado foram submetidos à carbonatação acelerada em uma câmara de carbonatação com teor de $10 \%$ de $\mathrm{CO}_{2}$, com umidade e temperatura controlada em $75 \pm 5 \%$ e $23 \pm 3^{\circ} \mathrm{C}$, respectivamente.

Uma vez constatada a despassivação das armaduras pela carbonatação, os corpos-de-prova foram submetidos a ciclos de 2 dias de imersão em uma solução alcalina de $\mathrm{KOH}$, e de 3 dias de secagem em estufa ventilada a $40^{\circ} \mathrm{C}$, durante um período total de 47 dias. A verificação da passivação antes de iniciar a carbonatação acelerada do concreto, a despassivação e a repassivação foram conferidas através das técnicas eletroquímicas de medida de potencial de corrosão (Ecorr) com eletrodo de 
referência de calomelano saturado e de Espectroscopia de Impedância Eletroquímica (EIE).

\section{Materiais e Métodos}

A relação água/cimento (a/c) adotada para a produção do concreto estudado teve como base o limite exigido pela norma brasileira "Projeto de estruturas de concreto - Procedimento" - NBR 6118 [5] para realização de estruturas de concreto armado, de a/c 0,65. Para tentar retratar, de forma adequada, a realidade dos concretos moldados nas obras foram definidas duas idades de cura, de 1 dia, e de 28 dias para as situações de cura em laboratório.

\subsection{Preparação dos Corpos-de-Prova}

Os corpos-de-prova foram prismáticos com dimensões de $10 \times 12 \times 4 \mathrm{~cm}$, e no interior dos mesmos foram colocadas duas armaduras de aço carbono convencionais submetidas ao procedimento de limpeza da norma americana ASTM G1 [6]. As barras foram revestidas com fita isolante, deixando apenas dois trechos não revestidos. Um dos trechos foi na extremidade que ficou fora do corpo-de-prova com 2 $\mathrm{cm}$ de comprimento para conectar os equipamentos para a realização dos ensaios de medidas eletroquímicas. Esta região das barras foi uma aplicada uma graxa condutora de cobre a fim de proteger as armaduras durante a cura e a carbonatação acelerada. O outro trecho foi na região que ficou imersa no concreto de $3 \mathrm{~cm}$ de comprimento, que delimitou a região da barra a ser despassivada [7].

As fôrmas produzidas para realização da moldagem dos corpos-de-prova foram de PVC, de forma a não precisar aplicar desmoldante na sua superfície

Passada as primeiras 24 horas da moldagem foi dado início à desmoldagem e à cura. A cura de 1 dia foi o período de 24 horas no qual o concreto se encontrou ainda na fôrma coberto com o filme de PVC. A cura de 28 dias foi realizada após a desmoldagem, que ocorreu depois de 24 horas, na qual os corposde-prova foram colocados na câmara úmida (a 100\% de umidade relativa) durante o período de 27 dias, completando assim os 28 dias de cura.

\subsection{Verificação da Frente de Carbonatação e de Realcalinização}

A verificação das frentes de carbonatação e de realcalinização foi realizada através da aspersão da fenolftaleína, o qual possibilitou a observação visual da área carbonatada na superfície recém fraturada dos corpos-de-prova sem armadura, chamado de "irmão". A metodologia para verificação da profundidade de carbonatação foi realizada conforme a recomendação da RILEM CPC-18 [8], sendo este o processo mais simples e de baixo custo para determinação da profundidade de carbonatação.

\subsection{Carbonatação Acelerada}

Depois de finalizada a cura, os corpos-de-prova aguardaram o período necessário para a formação da película de passivação (aproximadamente 3 meses). Após a constatação da passivação das armaduras, então os corpos-de-prova foram encaminhados ao ensaio acelerado de carbonatação.

A fim de carbonatar com rapidez os corpos-deprova moldados, comprometendo o mínimo possível a matriz do concreto, o ensaio de carbonatação acelerada foi realizado com concentração de $\mathrm{CO}_{2}$ de $10 \%$, umidade relativa (UR) interna da câmara de $75 \pm 5 \%$ e temperatura controlada em $23 \pm 3^{\circ} \mathrm{C}$.

\subsection{Realcalinização Química (RAQ)}

O sistema utilizado na realcalinização química, por absorção e difusão da solução de hidróxido de potássio P.A. na concentração molar de 2,5M, consistiu na realização de ciclos de imersão e secagem durante o tratamento. Cada ciclo durava 5 dias, onde nos dois primeiros dias os corpos-de-prova ficavam imerso na solução alcalina, e os três seguintes em uma estufa ventilada a $40^{\circ} \mathrm{C}$ para secar. Esses ciclos foram realizados para acelerar a penetração da solução alcalina no interior dos corpos-de-prova.

Durante a imersão dos corpos-de-prova em caixas com solução alcalina, a mesma teve o seu valor de $\mathrm{pH}$ monitorados a cada 3 dias, ao verificar a queda do 
valor de $\mathrm{pH}$ em um ponto, a solução era imediatamente troca.

\subsection{Técnicas de Medidas Eletroquímicas}

A finalidade deste ensaio foi verificar a condição eletroquímica da armadura no interior do concreto (passivada ou despassivada). A constatação do estado da armadura foi realizada através das técnicas eletroquímicas de medida do potencial de corrosão (Ecorr), através de um eletrodo de referência de calomelano saturado (ECS) conectado à um multímetro. E também da espectroscopia de impedância eletroquímica (EIE), através de um potenciostato e um detector de resposta em frequência (ou frequencímetro).

Uma vez que a maioria dos dados publicados em artigos, e na própria ASTM C876 [9], estabelece as faixas de probabilidade de corrosão no potencial obtido com o eletrodo de cobre/sulfato de cobre (ESC), torna-se interessante, a fim de facilitar as comparações entre artigos e trabalhos, a conversão do potencial obtido com o eletrodo de calomelano saturado (ECS) para o ESC. Segundo Wolynec [10], para tanto é necessário subtrair aos valores de potencial encontrado com o ECS a constante de 0,074 V (ou $74 \mathrm{mV}$ ).

\section{Materiais e Métodos}

\subsection{Passivação da Armadura no Interior do Concreto}

A determinação da passivação foi necessária para verificar o tempo necessário para a formação da mesma. Uma vez que a formação dessa película ao redor da armadura não ocorre imediatamente com a concretagem das peças. De acordo ${ }_{\text {COMPLAĈ́O }}$ as bibliografias estudadas, é necessário aguardar um período de tempo para a camada de óxidos de ferro se formar ao redor da armadura, e pode demorar de 7 dias [11] à quatro meses [12].

A formação da película de passivação só foi detectada após 3 meses da moldagem dos corpos-deprova. Durante todo esse período foram realizadas medidas periódicas de potencial de corrosão, as quais possibilitaram a constatação do aumento do potencial 113 de corrosão (menos eletronegativo) das barras com o passar do tempo. Ao final do segundo mês, a maioria das barras imersas no concreto de relação a/c 0,65 já apresentava um potencial de corrosão classificado com probabilidade de $5 \%$ (> -200 mV).

Com o intuito de esclarecer a dúvida quanto ao real estado da armadura, foram realizados os ensaios de EIE. Como esperado, os gráficos de EIE não deixaram qualquer dúvida quanto ao estado de passivação das armaduras, como pode ser observado nos gráficos da Figura 2.

Nos resultados de EIE obtidos durante o período de passivação da armadura, é possível observar a ascensão da curva do gráfico de Nyquist, característico de uma barra passivada (Figura 2 (a)). Qualitativamente a passivação da armadura é identificada pela ascensão constante da curva de Nyquist, e sem nenhum indício de fechamento do arco nas baixas frequências (menor que $10 \mathrm{~Hz}$ ).

Na Figura 2 (b) é possível observar que os altos valores de ângulo de fase máximos na baixa frequência no gráfico de Bode, embora não estivessem bem definidos, todos ficaram na faixa de $78^{\circ}$, bem próximo ao valor máximo de $90^{\circ}$, quando 0 comportamento da célula é puramente capacitivo [13].

Na Figura 2 (c) a grande inclinação de |Z| para as frequências abaixo de $10 \mathrm{~Hz}$, chega ao pico máximo de 51.400 ohms na frequência de $5 \mathrm{mHz}$, ou seja bastante resistivo à passagem de corrente elétrica.

Uma vez confirmada a formação da película de passivação, os corpos-de-prova foram colocados na câmara de carbonatação acelerada até que fosse constatada a total carbonatação do cobrimento do concreto, como também a despassivação das armaduras.

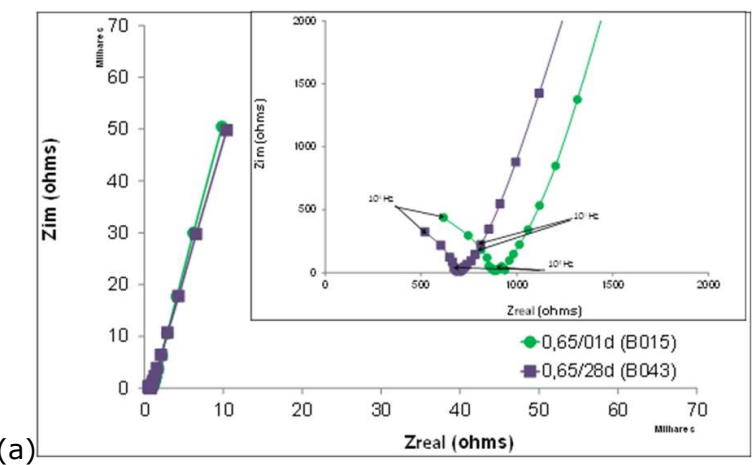



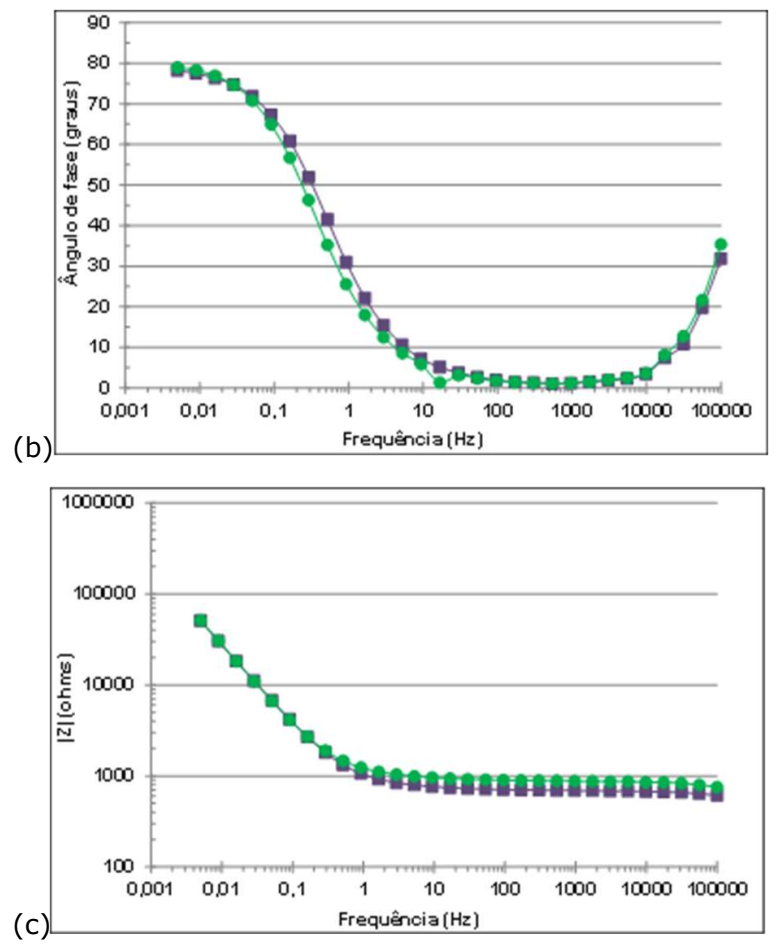

Figura 2 - Evolução dos espectros de impedância obtidos em concretos com os diferentes tempos de curas (01 e 28 dias) antes da carbonatação aos 5 meses de idade: (a) Diagrama de Nyquist com ampliação entre 0 e 2000 ohms, (b) e (c) Diagramas de Bode. Fonte: A autora.

\subsection{Despassivação da Armadura no Interior do Concreto}

A verificação da profundidade de carbonatação foi realizada através da fratura de corpos-de-prova moldados para esta finalidade, chamados de "irmãos" (corpos-de-prova também armados) dos que foram realcalinizados posteriormente, seguida da aspersão de uma solução alcoólica de fenolftaleína.

A determinação da despassivação da armadura através do potencial de corrosão somente foi realizada quando constatada a carbonatação do cobrimento dos corpos-de-prova "irmãos", através da aspersão de solução de fenolftaleína. As medidas de potencial de corrosão foram obtidas logo após a retirada dos corpos-de-prova da câmara de carbonatação acelerada sem a saturação dos mesmos. Ao verificar a alta eletronegatividade dos potenciais de corrosão, menor do que $-350 \mathrm{mV}$, indicando um potencial de probabilidade de corrosão de 95\% (Figura 3), então eram iniciados aos ensaios de EIE (Figura 4), para 114 determinar o estado da armadura, de forma a corroborarem com os resultados de potencial.
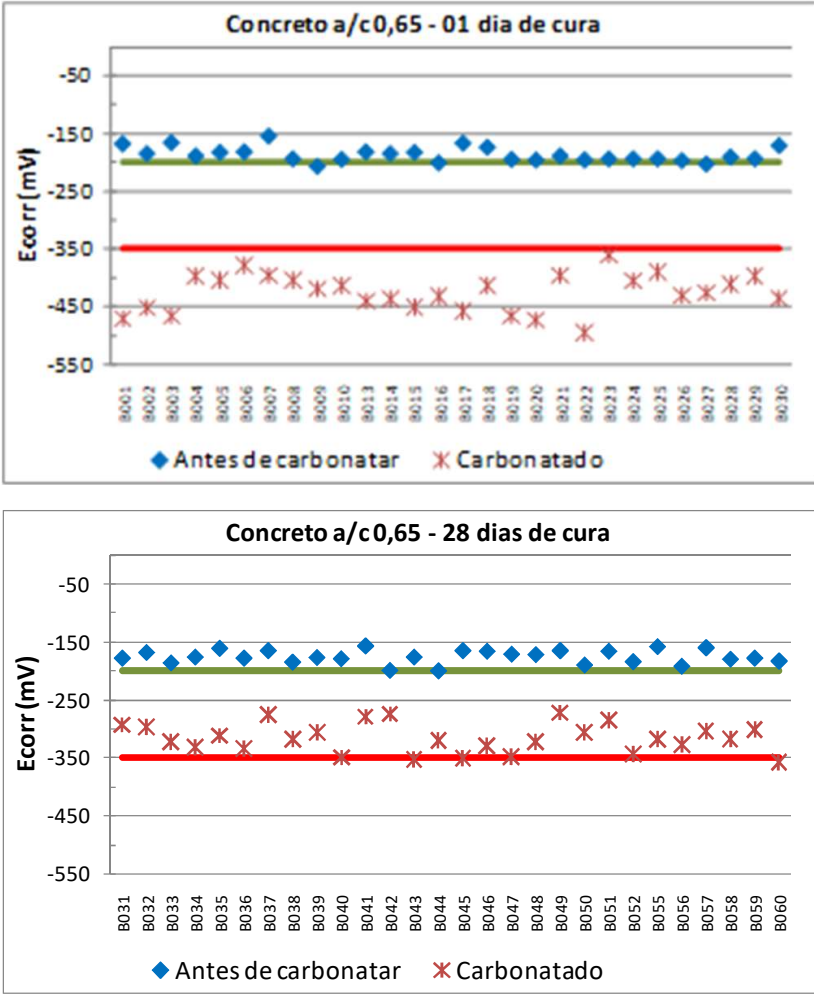

Figura 3 - Resultados de potencial de corrosão (Ecorr) antes de iniciar a carbonatação acelerada (na idade de 3 meses) e depois de carbonatado todo o cobrimento da armadura (armaduras despassivadas). Fonte: A autora.

Corroborando com os resultados de Ecorr das barras de concreto a/c 0,65 com 28 dias de cura apresentando uma probabilidade de corrosão de $50 \%$, os ensaios de EIE não deixaram dúvidas quando à despassivação das armaduras.

$\mathrm{Na}$ Figura 4 (a) utilizou-se uma ferramenta disponível no software "PowerSine" para realizar a extrapolação deste último arco incompleto, o que possibilita observar a tendência de fechamento do arco na amplitude do Zreal entre as frequências de $10 \mathrm{~Hz}$ e $5 \mathrm{mHz}$, que é característico em barras despassivadas.

http: / /dx.doi.org/10.25286/repa.v2i3.699 
(a)
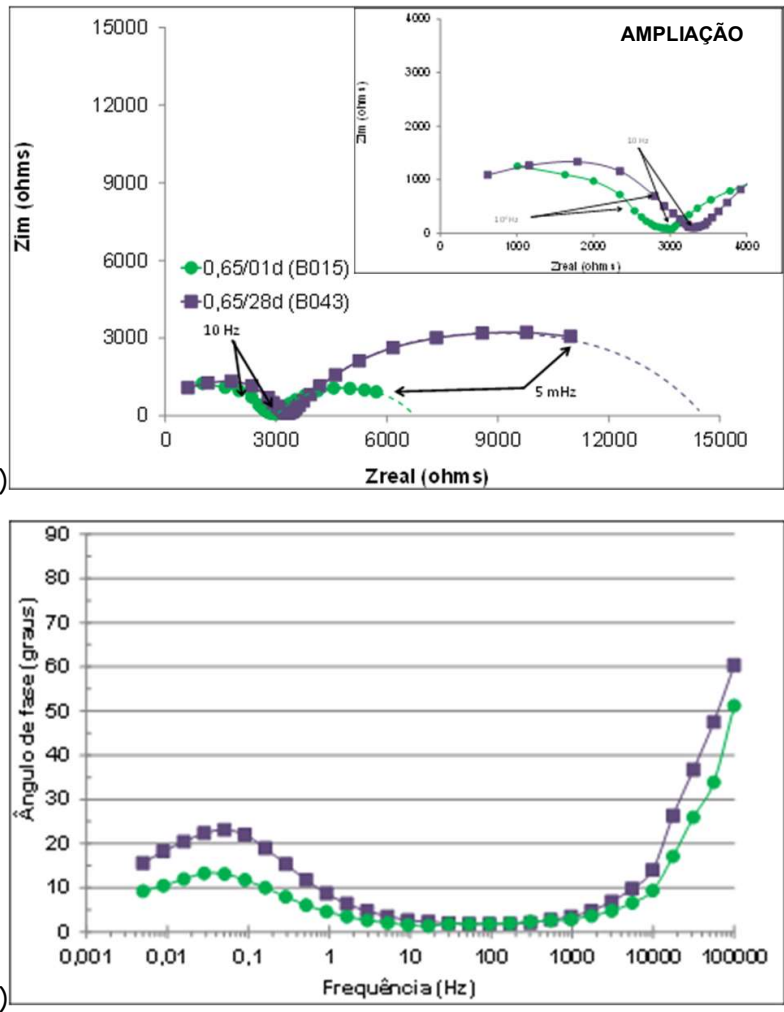

(b)

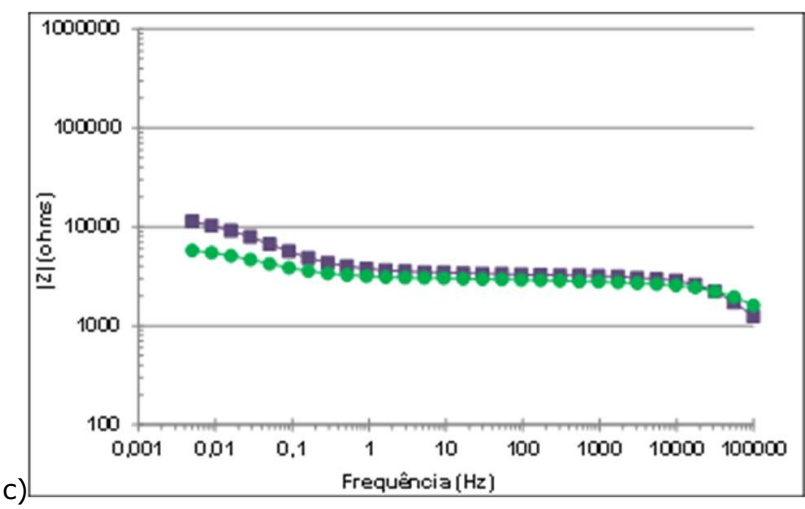

Figura 4 - Evolução dos espectros de impedância obtidos em concretos com diferentes tempos de curas (01 e 28 dias) totalmente carbonatados: (a) Diagrama de Nyquist com ampliação entre 0 e 4000 ohms, (b) e (c) Diagramas de Bode. Fonte: A autora.

Na Figura 4 (b) os ângulos de fase obtidos são bem menores do que os encontrados na Figura 3 (b), que eram de aproximadamente $80^{\circ}$, e agora entre $23^{\circ}$ e 130, característico de uma barra em estado de corrosão.

No diagrama de Bode da Figura 4 (c), o processo corrosivo é verificado pela mudança de inclinação do $|Z|$ em função da frequência, que na Figura 2 (c) 115 chegava a ordem de 51.000 ohms, ou seja, agora se encontra bem menos resistivo à passagem de corrente na baixa frequência.

Outro dado importante é o deslocamento das curvas de Nyquist (Figura 4 (a)) para a direita. Este deslocamento indica o aumento da resistência ôhmica de cada um dos concretos.

Com a comparação da ampliação da Figura 4 (a) com a da ampliação da Figura 2 (a), é possível observar o aumento da resistência ôhmica com a carbonatação. A carbonatação reduz a porosidade do concreto devido a formação de carbonato de cálcio nos poros do concreto. O carbonato de cálcio formado tem um volume maior do que o hidróxido de cálcio (um dos produtos formados na hidratação do clinquer), que estava originalmente nos poros. Desta maneira ocorre a redução da porosidade, e a resistência à passagem de corrente aumenta, ou seja, a resistência ôhmica, que é praticamente a resistividade elétrica, aumenta.

Após a confirmação da despassivação da armadura nos concretos carbonatados através dos ensaios de potencial de corrosão e de EIE, foi dado início aos processos de realcalinização química (RAQ).

\subsection{Repassivação da Armadura no Interior do Concreto}

A repassivação da armadura no interior do concreto ocorreu sem a indução de corrente elétrica, somente através da imersão dos corpos-de-prova na solução de 2,5M de hidróxido de potássio, promovendo a absorção e a difusão das soluções alcalina para o interior do concreto carbonatado (realcalinização química - RAQ).

A identificação da recuperação da película de passivação foi realizada a partir da obtenção de valores de potencial de corrosão menos eletronegativo ( $>-200 \mathrm{mV}$ ). Além da identificação da curva de Nyquist sem a formação do último arco no ensaio de EIE.

Os corpos-de-prova imersos na solução de hidróxido de potássio depois de 47 dias apresentaram total realcalinização do cobrimento.

As primeiras medidas de potencial de corrosão (Figura 5) foram realizadas logo após a finalização dos 
ensaios com os corpos-de-prova ainda saturados. Assim como a constatação da realcalinização pela aspersão dos indicadores colorimétricos de $\mathrm{pH}$ no cobrimento do concreto, foi possível verificar a repassivação da armadura após 3 meses de finalizado o tratamento de RAQ. No gráfico da Figura 5 é possível observar a evolução do potencial de corrosão com 1 , 3 e 6 meses após finalização da RAQ.

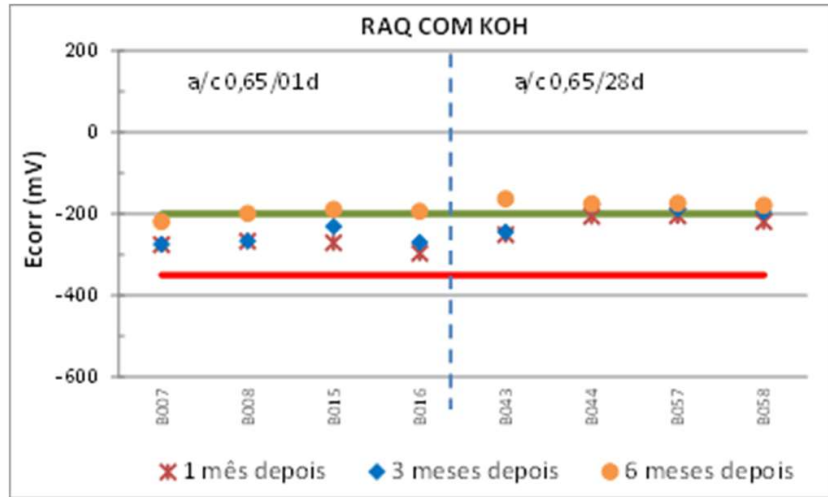

Figura 5 - Evolução do potencial de corrosão logo após a finalização do tratamento, e com 1, 3 e após 6 meses de finalização da RAQ com os corpos-de-prova com 1 dia e 28 dias de cura. Fonte: A autora.

A solução alcalina de hidróxido de potássio depois de três meses já apresentava potenciais de corrosão eletropositivo, mantendo-se na faixa de probabilidade de corrosão inferior a $5 \%(-200 \mathrm{mV})$. Isto aconteceu devido a sua capacidade de realcalinizar o concreto ao redor da armadura, propiciando a repassivação da mesma.

Aos 4 meses de finalizado o tratamento foram realizados os ensaios de EIE com os corpos-de-prova realcalinizados com a solução alcalina de hidróxido de potássio. Nas Figuras 6 e 7 é possível observar a situação de passivação das armaduras antes da carbonatação e depois de 4 meses de finalizado o tratamento de RAQ.
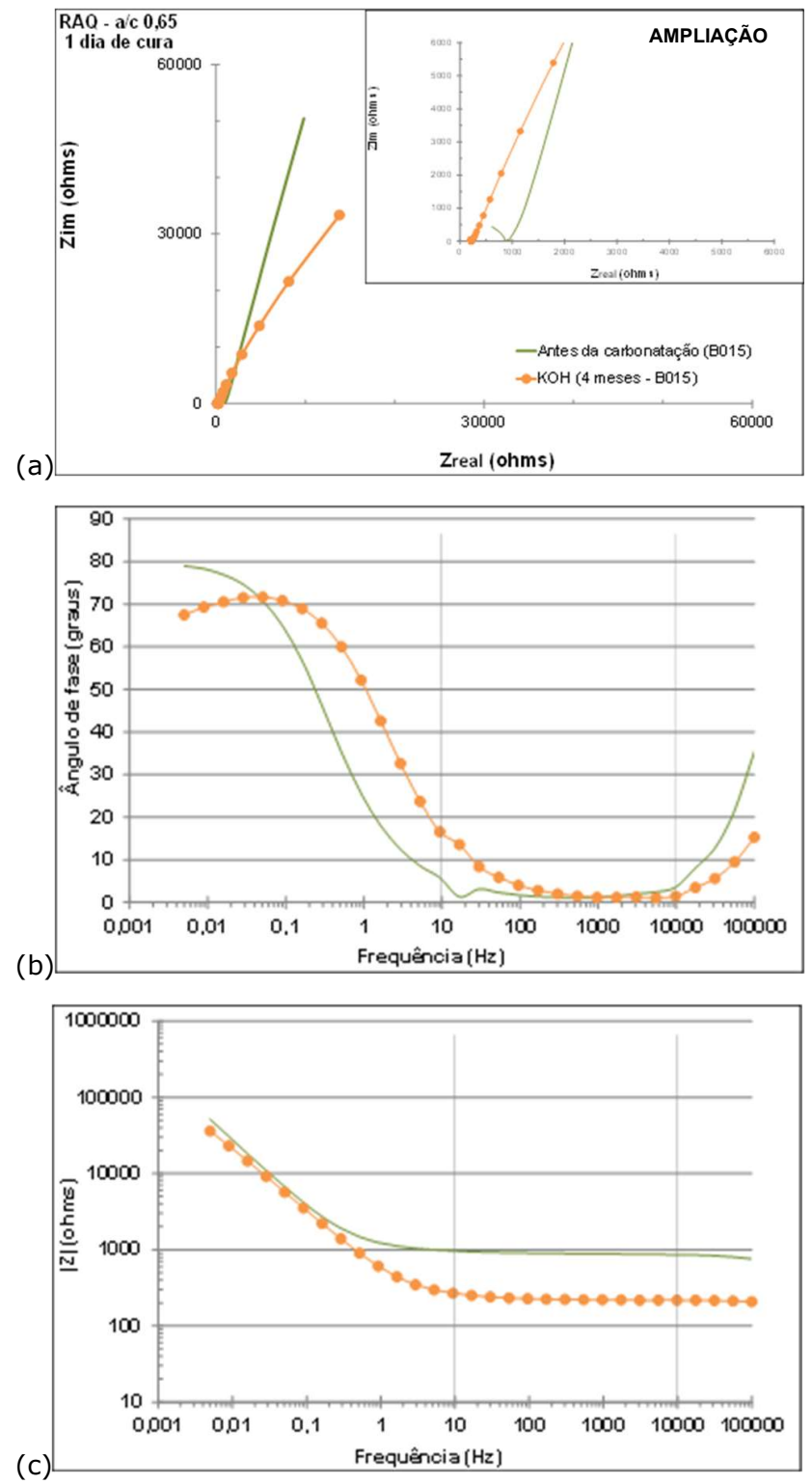

Figura 6 - Evolução dos espectros de impedância nas armaduras imersas no concreto de relação a/c 0,65 e tempos de cura de 1 dia: (a) Diagrama de Nyquist, (b) e (c) Diagramas de Bode. Fonte: A autora. 

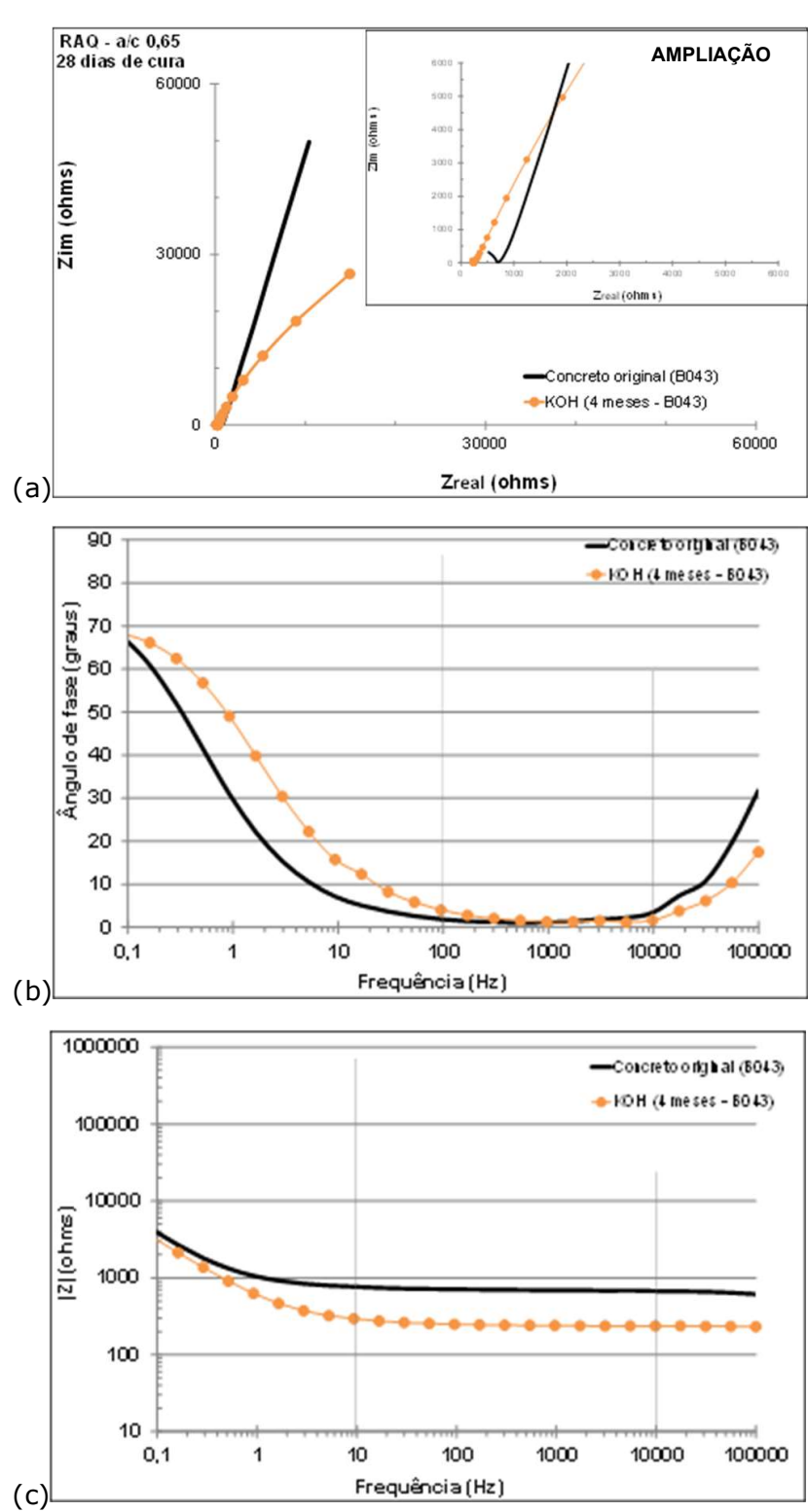

Figura 7 - Evolução dos espectros de impedância nas armaduras imersas no concreto de relação a/c 0,65 e tempos de cura de 28 dias: (a) Diagrama de Nyquist, (b) e (c) Diagramas de Bode. Fonte: A autora.

A utilização da solução de hidróxido de potássio apresentou um bom comportamento após a RAQ, com valores de ângulo de fase bem próximos aos de antes da carbonatação, e valores de impedância bastante altos.

\section{Conclusões}

Com relação ao concreto após a realcalinização química com hidróxido de potássio, a resistência ôhmica do concreto após a carbonatação foi maior do que no concreto de controle (referência). Este comportamento confirma o que é relatado na bibliografia, onde a carbonatação, do ponto de vista apenas do concreto, proporciona o fechamento dos seus poros. Com a RAQ o concreto apresentou uma resistência ôhmica menor do que no concreto de controle (referência). Ou seja, este ensaio mostrou que provavelmente os compostos formados em razão da RAQ com a solução ocupam um espaço menor do que os compostos formados originalmente durante a hidratação do cimento.

De acordo com o levantamento bibliográfico realizado, a solução de hidróxido de potássio é considerada como a solução alcalina mais propícia para utilizar na realcalinização química. No entanto, os potenciais de corrosão obtidos nas barras após o tratamento com a técnica de RAQ ainda se mostraram mais eletronegativos, do que o esperado. No entanto, nos resultados de EIE, a solução apresentou resultados de impedância, de $|Z|$ e de ângulo de fase próximos aos da barra antes da despassivação, o que indica uma eficiência no processo de repassivação da armadura.

É importante ressaltar, que, de acordo com a bibliografia estudada, o estágio de propagação no qual a corrosão se encontra vai ser determinante para o sucesso ou insucesso da realcalinização. Assim, caso a armadura se encontre em um estágio avançado de corrosão, é possível que a RAQ não proporcione a sua repassivação.

\section{Referências}

[1] RÉUS, G. C. Realcalinização química como meio de recuperação de estruturas de concreto armado carbonatadas. 2017. 97f. Dissertação (Mestrado em Engenharia de Construção Civil) Universidade Federal do Paraná, Curitiba.

[2] ARAÚJO, F. W. C. Contribuição à viabilização da técnica de realcalinização do concreto carbonatado através da absorção/difusão de soluções alcalinas. 2004. 157f. Dissertação (Mestrado em Engenharia Civil) - Universidade Federal de Goiás, Goiânia. 
[3] SÁ, R. R. Influência da realcalinização por meio da absorção/difusão de soluções alcalinas na resistência à compressão do concreto, na aderência de tintas e vernizes e na repassivação da armadura. 2006. 155f. Dissertação (Mestrado em Engenharia Civil) - Universidade Federal de Goiás, Goiânia.

[4] MOREIRA, C. Realcalinização de estruturas de concreto carbonatado com utilização de gel saturado de solução alcalina. 2006. $123 f$. Dissertação (Mestrado em Engenharia Civil) Universidade Federal de Goiás, Goiânia.

[5] ASSOCIAÇÃO BRASILEIRA DE NORMAS TÉCNICAS. NBR-6118. Projeto de estruturas de concreto - Procedimento. Rio de Janeiro: ABNT, 2014.

[6] AMERICAN SOCIETY FOR TESTING AND MATERIALS. ASTM-G1. Standard practice for preparing, cleaning, and evaluating corrosion test specimens. Annual Book of ASTM Standards. Philadelphia. 2003.

[7] ARAÚJO, F. W. C. Estudo da repassivação das armaduras em concretos carbonatados através da técnica de realcalinização química. 2009. 212f.Tese (Doutorado em Engenharia Civil) Escola Politécnica da Universidade de São Paulo, São Paulo.

[8] RILEM. Measurement of hardened concrete carbonation depth. RILEM CPC-18 Recommendation. Materials and structures journal, v. 21, p. 453-455, 1988.

[9] AMERICAN SOCIETY FOR TESTING AND MATERIALS. ASTM-C876: Standard test method for half-cell potential of uncoated reinforcing steel in concrete. Annual Book of ASTM Standards. Philadelphia. 1991.

[10] WOLYNEC, S. Técnicas eletroquímicas em corrosão. São Paulo: Editora da Universidade de São Paulo-EDUSP, 2003. 166p.

[11] POURSAEE, A.; HANSSON, C.M. Reinforcing steel passivation in mortar and pore solution. Cement and Concrete Research, v. 37, p. 11271133, 2007.
[12] ARAÚJO, F. W. C.; FIGUEIREDO, E. P.; HELENE, P. Contribuição para a viabilização da técnica de realcalinização do concreto carbonatado: repassivação da armadura. In. $49^{\circ}$ CONGRESSO BRASILEIRO DO CONCRETO CBC2007. Bento Gonçalves, Brasil. 2007.

[13] AOKI, I.V. Corrosão e Processos de Proteção em Materiais Metálicos. Apostila de aula: Disciplina: PQI5760. 30 Quadrimestre de 2008. Universidade de São Paulo - USP. São Paulo, Brasil. 